\title{
Circulating Antigens and Antibodies in Human and Mouse Dermatophytosis: Use of Monoclonal Antibody Reactive to Phosphorylcholine-like Epitopes
}

\author{
By R. A. CALDERON,* R. J. HAY AND G. I. SHENNAN \\ Department of Medical Microbiology, Medical Mycology and Tropical Dermatology Unit, \\ London School of Hygiene and Tropical Medicine, Keppel Street (Gower Street), \\ London WCI 7 HT, UK
}

(Received 26 February 1987; revised 22 April 1987)

\begin{abstract}
The presence of circulating antibodies in the sera of patients infected with either Trichophyton concentricum or Trichophyton rubrum, and in the sera of BALB/c mice chronically infected with Trichophyton quinckeanum, was determined by ELISA. High levels of antibody to dermatophyte cytoplasmic antigens were detected both in infected humans and in mice. Partial inhibition of - this reaction was observed by pretreatment of the sera with the hapten phosphorylcholine (PC). Moreover, antibodies were shown to have some reactivity with PC when tested by ELISA against PC conjugated to bovine serum albumin. Significant levels of circulating antigen were detected in patients with $T$. concentricum and $T$. rubrum infections, but not in uninfected subjects, by an immunoradiometric assay using a monoclonal antibody, Tq-1, which reacts with the PC-like epitopes of dermatophytes. It is possible that this dermatophyte antigen may play a role in modulating the cell-mediated immune responses, which would appear to be defective in most patients with these chronic forms of dermatophytosis.
\end{abstract}

\section{INTRODUCTION}

Dermatophyte fungi cause superficial infections by invading keratinized tissue of the skin, hair and nails of humans and animals. A distinctive characteristic of dermatophytes which makes them unique is that fungal invasion limited to the keratinized layers of the epidermis can elicit strong humoral and cell-mediated immune responses (Grappel et al., 1974; Lepper, 1969; Jones et al., 1974). However, in spite of this potential for immune expression some dermatophyte species cause persistent and recurrent infections.

In humans, two contrasting types of dermatophyte infections may occur. Zoophilic species of dermatophytes such as Trichophyton mentagrophytes usually cause an inflammatory infection which may heal spontaneously and results in resistance to reinfection. Anthropophilic species such as Trichophyton rubrum and Trichophyton concentricum, however, cause persistent infections, do not elicit significant inflammatory responses and are often resistant to therapy. The reasons for the disparity in the disease process caused by zoophilic and anthropophilic species are as yet unknown. However, although antibodies are produced in response to both types of infections, cell-mediated immunity, as judged by delayed-type hypersensitivity, is more readily detected in the inflammatory infections (Jones et al., 1974); chronic infections have been correlated with specific defective T-lymphocyte activity (Hanifin et al., 1974).

In experimentally infected mice it has been shown that adoptive immunity can be abrogated by serum from chronically infected mice (Calderon \& Hay, 1984b) and that administration of alum-adsorbed specific antigen may prolong and exacerbate subsequent experimental infection.

Abbreviations: PC, phosphorylcholine; CA, cytoplasmic antigen; IRMA, immunoradiometric assay. 
Circulating dermatophyte antigens have been detected by ELISA in infected animals and it is possible that soluble fungal antigens produced in vivo may play an important role in modulating the host immune response.

These observations suggest that a more detailed knowledge of dermatophyte antigens and their interaction with the cells of the host immune system is essential to understanding the immunopathogenesis of the disease. This in turn requires the ability to detect monospecific antigens. In the present study we have analysed the sera of patients infected with either $T$. rubrum or $T$. concentricum, for circulating antigen using a monoclonal antibody. This antibody, $\mathrm{Tq}-1$, directed against phosphorylcholine (PC)-like epitopes common to dermatophytes is described in the accompanying paper (Calderon \& Shennan, 1987). We have also investigated the presence of circulating antibodies in dermatophyte infected humans and mice, and their reactivity to $\mathrm{PC}$.

\section{METHODS}

Dermatophyte species. T. concentricum (NCPF 567), T. quinckeanum (NCPF 309) and T. rubrum (NCPF 633) were obtained from the National Collection of Pathogenic Fungi (NCPF), Mycology Reference Laboratory, PHLS Colindale, London.

Dermatophyte antigen preparation. Fungal cytoplasmic antigens (CAs) were prepared as described in the accompanying paper (Calderon \& Shennan, 1987).

Human sera. The patients with dermatophytosis comprised two groups. The first were patients with $T$. rubrum infections affecting the body (tinea corporis), palms or soles. These patients were attending the outpatient department of St John's Hospital for Diseases of the Skin, London. The second group were patients with tinea imbricata, an extensive and chronic infection caused by $T$. concentricum. Sera were obtained from patients residing in an area (Milne Bay and West Sepik Provinces, Papua New Guinea) in which tinea imbricata is endemic. Clinical features of these infections were described by Hay et al. (1984). Control sera were obtained from individuals residing in London or Papua New Guinea with no history of dermatophyte infection.

Mouse sera. The methods of induction of chronic dermatophyte infection in BALB/c mice (obtained from the National Institute for Medical Research, London) with T. quinckeanum, and mouse immunization with CAs are described in the accompanying paper (Calderon \& Shennan, 1987).

Treatment of human and mouse sera with PC. In some experiments human and mouse sera and monoclonal antibody Tq-1 were pretreated with cytidine-5'-diphosphocholine (Sigma) to give a final concentration of $10 \mathrm{nM}$, and incubated for $1 \mathrm{~h}$ at $37^{\circ} \mathrm{C}$. Samples were then centrifuged at $20000 \mathrm{~g}$ for $10 \mathrm{~min}$ and the supernatant used for subsequent antibody assays.

Radioiodination of Tq-1 monoclonal antibody. Protein-A affinity purified Tq-1 monoclonal antibody (Calderon \& Shennan, 1987) was labelled with [ $\left.{ }^{125} \mathrm{I}\right]$ iodide (Amersham) by the Iodo-gen (1,3,4,6-tetrachloro-3 $\alpha, 6 \alpha-$ diphenylglycoluril) technique described by Markwell \& Fox (1978) and summarized in the accompanying paper (Calderon \& Shennan, 1987). The radiolabelled antibody showed a precipitability index with TCA of $98 \%$.

ELISA. This was used to detect circulating antibodies to fungal CAs and to PC in humans and mice. Microtitre plates were coated with $100 \mu \mathrm{l}\left(10 \mu \mathrm{g}\right.$ protein $\left.\mathrm{ml}^{-1}\right)$ of $T$. concentricum, $T$. rubrum or T. quinckeanum CA or with $100 \mu \mathrm{l}\left(1 \mu \mathrm{g} \mathrm{ml}^{-1}\right)$ cytidine-5'-diphosphocholine conjugated to bovine serum albumin (BSA-PC) (donated by $\mathrm{Dr}$ R. M. Maizels, Imperial College, London). The procedure and reagents are described in the accompanying paper (Calderon \& Shennan, 1987). Peroxidase-conjugated goat anti-mouse polyvalent Ig (Sigma), goat anti-human IgG, and goat anti-human IgM (Sigma), and the substrate $o$-phenylenediamine were used in this study.

Immunoradiometric assay (IRMA). This was done with the modification of Forsyth et al. (1985) and was used to detect circulating dermatophyte antigens in humans. Briefly, polyvinylchloride (PVC) plates (Dynatech) were incubated overnight with $50 \mu \mathrm{l}$ per well of a $10 \mu \mathrm{g} \mathrm{m}{ }^{-1}$ solution of protein-A-affinity-purified Tq-1 monoclonal antibody in PBS. Plates were washed three times with $0.05 \%(\mathrm{v} / \mathrm{v})$ Tween $20 / \mathrm{PBS}$, and incubated with $50 \mu 10.5 \%$ (w/v) BSA in PBS for $30 \mathrm{~min}$ at room temperature. In the wells of an uncoated duplicate PVC plate $60 \mu \mathrm{l}$ of ${ }^{125} \mathrm{I}-$ labelled monoclonal antibody containing $6 \times 10^{4} \mathrm{c}$.p.m. were mixed with $60 \mu \mathrm{l}$ of human serum diluted $1: 5$ in $5 \%$ normal rabbit serum in $0.05 \%$ Tween/PBS and incubated for $6 \mathrm{~h}$ at $37^{\circ} \mathrm{C}$; samples of equal volume from each well were transferred to two wells $(50 \mu \mathrm{l}$ per well) of a washed Tq-1 coated plate. The plate was incubated overnight at room temperature and washed three times with $0.05 \%$ Tween/PBS; individual wells were excised, placed in vials and counted in a gamma counter (LKB 1280 Ultrogamma).

Statistics. Standard error was used as an estimate of variance, and means were compared by Student's two-tailed $t$-test for independent means. 

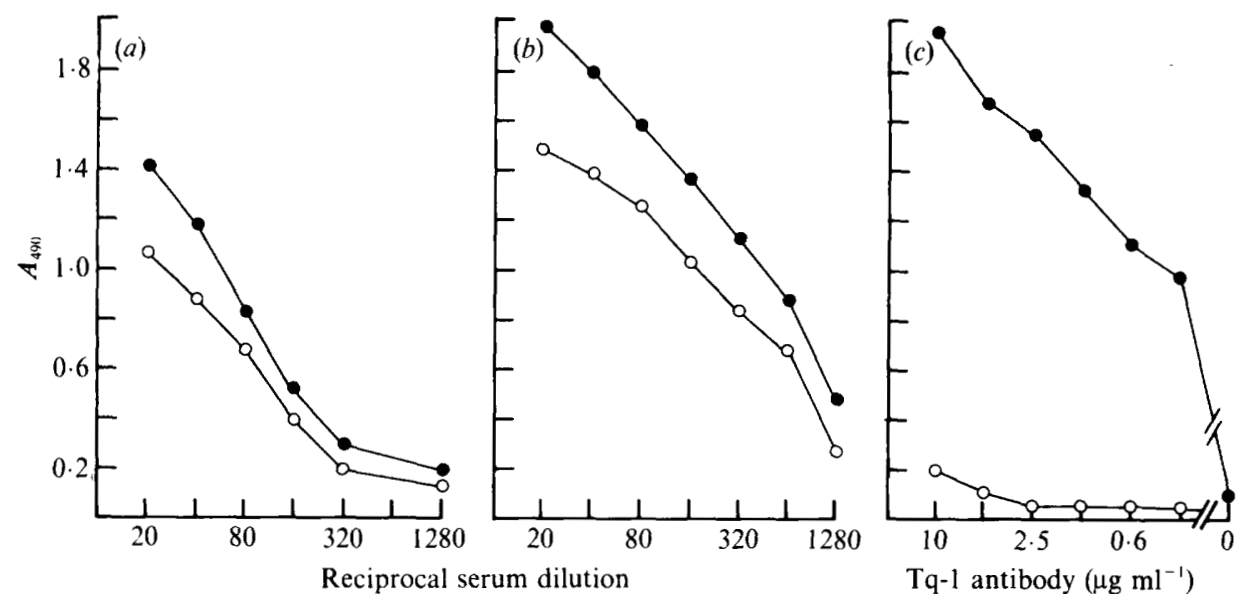

Fig. 1. Effect of PC treatment of mouse anti-dermatophyte antibody on antigen binding by ELISA. Microtitre plates were sensitized with $T$. quinckeanum CA $\left(10 \mu \mathrm{g} \mathrm{ml}^{-1}\right)$. Reaction was measured with peroxidase-conjugated goat anti-mouse polyvalent Ig. (a) Sera from immune mice; (b) sera from chronically infected mice; $(c)$ monoclonal antibody $\mathrm{Tq}-1$. O, Mouse anti-dermatophyte antibody after treatment with $10 \mathrm{nM}-\mathrm{PC}$ for $1 \mathrm{~h}$ at $37^{\circ} \mathrm{C}$;, control done in the absence of PC.

\section{RESULTS}

Detection of antibodies to $P C$ in serum of $T$. quinckeanum immune and infected mice

The presence of circulating antibodies with specificity to $\mathrm{PC}$ in the serum of mice chronically infected ( 8 weeks) with $T$. quinckeanum, or immunized with fungal CA, was determined by ELISA using BSA-PC coated microtitre plates and peroxidase-conjugated goat anti-mouse IgG. Although sera from both immune and chronically infected mice were reactive with PC, the chronic sera showed stronger reactivity $(P<0.001)$. The sera from uninfected mice, however, did not react with PC, indicating that induction of antibodies to PC was the result of specific dermatophyte antigen stimulation.

\section{Effect of PC treatment of immune and infected mouse sera on reactivity to dermatophyte antigens}

To estimate the binding activity to PC-like dermatophyte antigens, sera from immune or chronically infected mice were pretreated with PC hapten and tested in an ELISA system using fungal CA-coated microtitre plates. High titres of circulating antibody were detected in chronic sera. A partial but significant inhibition of binding to fungal antigens was observed after treatment of serum with PC $(P<0.001$ at $1: 20$ and $1: 40$, and $P<0.05$ at $1: 80-320$ serum dilutions) (Fig. $1 b$ ). In immune sera antibody was also detected, but here inhibition by PC was less pronounced $(P<0.05$ at $1: 20$ and $1: 40$ serum dilution) (Fig. $1 a)$. On the other hand, the binding activity of Tq-1 monoclonal antibody to fungal CA was completely inhibited by PC (Fig. 1c). Sera from uninfected mice did not react with fungal CA in an ELISA, and background readings of 0.08 to 0.12 at $A_{490}$ were regularly obtained.

\section{Detection of antibodies to $P C$ in serum of infected patients}

In a similar manner to mouse sera, antibodies to PC were detected in sera of human subjects infected with $T$. concentricum. In these patients, IgM class antibodies to PC were present at higher levels than IgG antibodies (Fig. $2 a, b$ ). Human sera from uninfected subjects also showed reactivity to $\mathrm{PC}$; however, the antibody titre was significantly lower than in patients, with $P<0.001$ for IgM at $1: 10-1: 160$ serum dilution and $P<0.03$ for IgG at $1: 10$. Similar results were obtained with sera of patients infected with $T$. rubrum. For instance, the $A_{490}$ values for anti-IgG response were: $1: 10(0 \cdot 28 \pm 0 \cdot 09), 1: 40(0 \cdot 23 \pm 0 \cdot 10)$, and $1: 160(0 \cdot 15 \pm 0 \cdot 03)$; and for anti-IgM were: $1: 10(0 \cdot 85 \pm 0 \cdot 14), 1: 40(0 \cdot 72 \pm 0 \cdot 19)$ and $1: 160(0 \cdot 49 \pm 0 \cdot 10)$. 


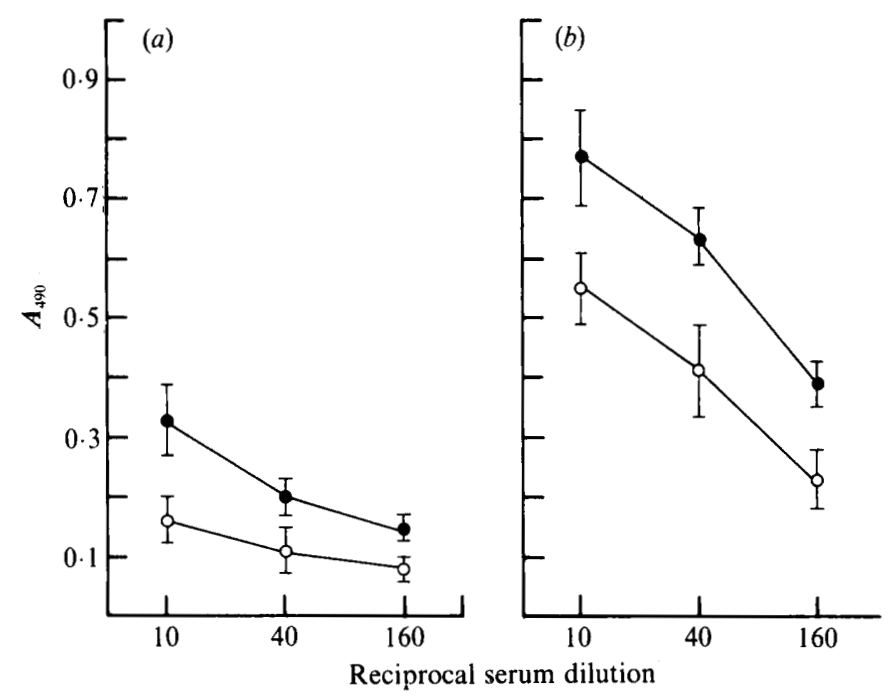

Fig. 2. Detection of anti-PC antibody in human sera by ELISA. Plates were sensitized with BSA-PC $\left(1 \mu \mathrm{g} \mathrm{ml}^{-1}\right)$ and reaction was measured with peroxidase-conjugated goat anti-human $\operatorname{IgG}(a)$ or $\operatorname{IgM}(b)$. , Sera from patients infected with $T$. concentricum; $O$, normal human sera. Values represent the arithmetic mean \pm SEM of 40 patients and 20 uninfected subjects.

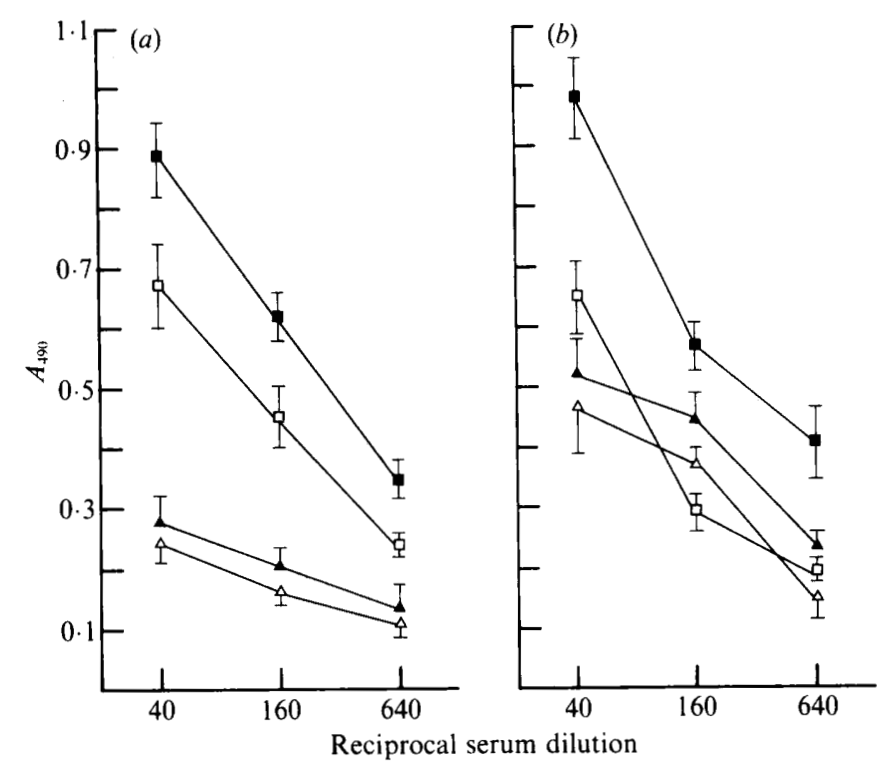

Fig. 3. Effect of PC treatment of human anti-dermatophyte antibody on antigen binding by ELISA. Microtitre plates were sensitized with $T$. concentricum CA $\left(10 \mu \mathrm{g} \mathrm{ml}^{-1}\right)$. Reaction was measured with goat anti-human $\operatorname{IgG}(a)$ or IgM $(b)$. $\square$, Sera from $T$. concentricum patients after treatment with PC; $\square$, control done in the absence of PC. $\triangle$, Normal human sera after treatment with $P C ; \boldsymbol{\Delta}$, control done in the absence of PC. Values represent the arithmetic mean \pm SEM of 40 patients and 20 uninfected subjects.

\section{Effect of $P C$ treatment of sera of infected patients on reactivity to $C A S$}

Circulating antibody to CAs was detected in the sera of patients infected either with $T$. concentricum or with T. rubrum. The results in Fig. 3 show a strong IgG and IgM antibody reaction in sera of $T$. concentricum patients. This binding activity was partially but significantly reduced by pretreatment of sera with $\mathrm{PC}$ hapten, with $P<0.001$ for $\operatorname{IgM}$, and $P<0.02$ for IgG. 

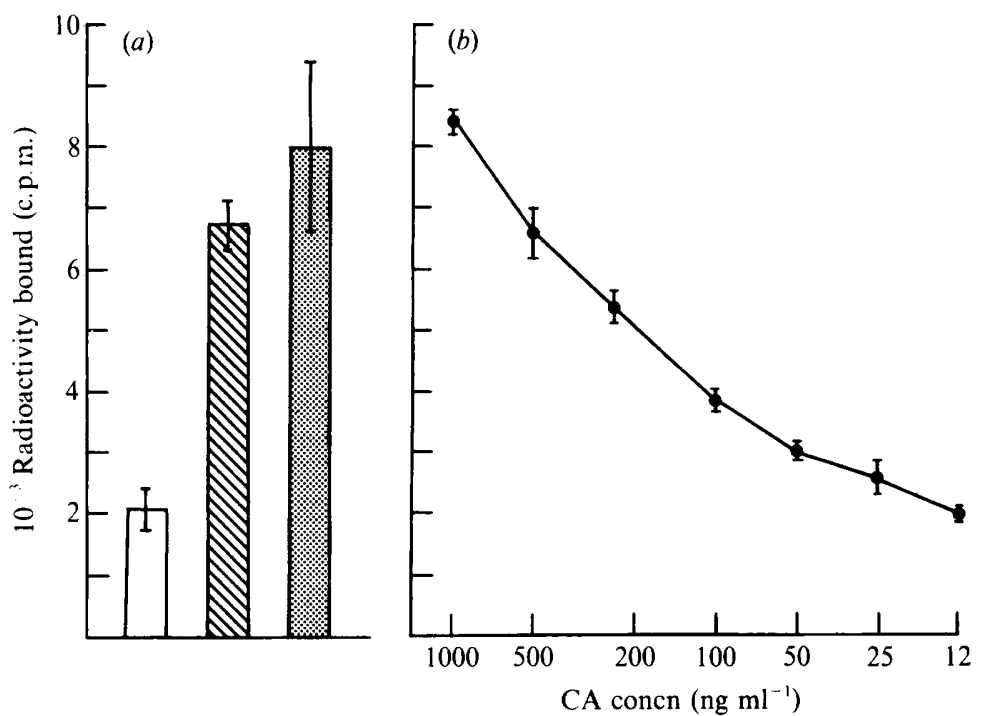

Fig. 4. Detection of Tq-1 target antigen in the sera of $T$. concentricum and $T$. rubrum patients by IRMA. IRMA was carried out by a sequential sandwich procedure as detailed in Methods. Values represent the arithmetic mean \pm SEM of 40 patients with T. concentricum ( $\$$ ), 20 patients with $T$. rubrum ( $(20$ ) and 20 uninfected subjects $(\square)$.

Similar results were obtained with sera of $T$. rubrum infected patients. For instance, the $A_{490}$ values for anti-IgG response were: $1: 40(0.95 \pm 0 \cdot 20 ;+\mathrm{PC} 0 \cdot 70 \pm 0 \cdot 12), 1: 160(0 \cdot 70 \pm 0 \cdot 17$; + PC $0.42 \pm 0.09), 1: 640(0.45 \pm 0.07 ;+$ PC $0.26 \pm 0.04) ;$ and for anti-IgM were: $1: 40$ $(0.91 \pm 0.21 ;+$ PC $0.76 \pm 0.10), 1: 160(0.63 \pm 0.15 ;+$ PC $0.29 \pm 0.05), 1: 640(0.54 \pm 0.12 ;$ $+\mathrm{PC} 0.27 \pm 0 \cdot 17)$. A less pronounced, but nonetheless significant reaction to $\mathrm{CA}$ was found in the sera of uninfected subjects. This result was not unexpected since these sera showed some reactivity to PC (Fig. 2), known to be present in fungal antigens.

\section{Detection of circulating Tq-1 target antigen in the sera of dermatophyte infected patients}

Antigen cross-reactivity between species is a characteristic of dermatophytes. Previous work using crossed-immunoelectrophoresis has shown that whole-cell antigens derived from dermatophyte species contain numerous antigenic peaks and that there is strong cross reactivity between different organisms (Svejgaard, 1985). Thus, in this study the Tq-1 antibody, which has been demonstrated to react with both $T$. concentricum and $T$. rubrum CAs, was used as a probe for detection of circulating antigens in patients infected with these organisms. Sera were tested in a one-antibody two-site IRMA for Tq-1 target antigens in circulation. The results of this study showed significant levels of circulating antigen in patients with $T$. rubrum and in those with $T$. concentricum infections (Fig. 4). Low antigen titres were found in the sera of uninfected subjects with $P<0.0001$ compared to infected patients. It was also found that by the IRMA technique $\mathrm{Tq}-1$ can detect dermatophyte antigen in the presence of CA (12 ng protein $\left.\mathrm{ml}^{-1}\right)$ (Fig. 4).

\section{DISCUSSION}

The present study examined the significance of the PC hapten, present in dermatophyte antigens, in relation to the humoral response of infected humans and experimentally infected mice. In the accompanying paper (Calderon \& Shennan, 1987) we showed that a monoclonal antibody, designated Tq-1, derived from mice immunized with an alum-adsorbed fraction of dermatophyte $\mathrm{CA}$ had a strong affinity for PC-bearing fungal components. Here, antibodies to PC were detected both in the serum of mice infected with $T$. quinckeanum and in those immunized with fungal antigens, but none were detected in uninfected mice, indicating that PC- 
reactive antibodies were elicited by dermatophyte antigens. Furthermore, the reaction of dermatophyte antigen with specific antibody from infected or immunized mice was partially inhibited with the PC hapten (Fig. 1), suggesting that a proportion of this antibody response was directed to the PC epitopes.

In humans, IgM antibodies with affinity for PC were found in both uninfected and dermatophyte infected individuals. However, this activity was significantly more pronounced in patients with dermatophytosis (Fig. $2 a$ ). It is not known whether there is any cross-reactivity with bacteria containing PC-like antigens which might explain the levels of antibodies occurring in controls. Anti-IgG antibodies, on the other hand, were present in low concentration in patients, but absent in uninfected individuals (Fig. $2 b$ ). Specific IgG and IgM antibody responses to CAs were present in patients infected with either $T$. rubrum or $T$. concentricum (Fig. 3) and this antigen-antibody reaction was partially inhibited with PC hapten; PC binding inhibition of patient sera was, however, more significant than in controls.

Antibody responses to antigens occur during dermatophyte infections in humans and animals (Grappel et al., 1974). Thus, in order to establish their significance in the clinical course of the infection the nature of dominant antigenic determinants needs to be defined. In our accompanying paper (Calderon \& Shennan, 1987) the results indicated that the hapten PC, a structural component of dermatophytes (Baldo et al., 1977), appeared to be a dominant antigen during dermatophyte infections in mice. The hapten PC, found also in bacteria (Brundish \& Baddiley, 1968) and parasites (Pery et al., 1974), binds to the acute phase C-reactive protein and the resulting complex is known to elicit some immunological reactions (Kaplan \& Volanakis, 1974).

Dermatophyte infections in humans and animals often result in temporal suppression of specific and non-specific cell-mediated immune functions such as lymphocyte blastogenesis to T-cell and B-cell mitogens (Hanifin et al., 1974; Green \& Balish, 1979; Calderon \& Hay, 1984a). S. Mayou, R. A. Calderon, R. J. Hay \& A. Goodfellow (unpublished data) showed that the in vitro non-specific and specific blastogenic responses to the T-cell mitogen concanavalin $A$ and to dermatophyte CA were severely reduced in a patient with deep dermatophytosis only in the presence of autologous, but not of heterologous serum, suggesting the presence of humoral blocking factors. The presence of blocking factors in serum of dermatophyte infected patients has been reported (Walters et al., 1974; Allen et al., 1977), but the putative blocking factors in human dermatophytosis have not yet been defined. In mice experimentally infected with $T$. quinckeanum the adoptive cell-mediated immunity was abrogated with specific antigens (Calderon \& Hay, 1984b). In the present study, circulating Tq-1 target antigens, PC-bearing components, were found in patients with infections caused by $T$. rubrum localized to the palms or soles as well as in those with more widespread tinea corporis caused by $T$. rubrum and $T$. concentricum (Fig. 4). This is apparently the first time that circulating antigens of dermatophyte fungi have been detected in infected patients. Whether the PC-bearing dermatophyte antigens in circulation are present alone and/or complexed to antibody, or whether they may in any way be responsible for the impairment of cell-mediated immune function is not yet clear; studies of this question are in progress. However, the patients investigated all had titres of circulating PCbearing antigen in association with chronic dermatophytosis, and patients with T. rubrum or $T$. concentricum infections have defective cell-mediated immune responses (Hanifin et al., 1974; Hay et al., 1983). It could be interesting to compare these findings with patients infected with dermatophytes such as $T$. mentagrophytes where lesions are more inflammatory and result in effective cell-mediated immune responses.

Dermatophyte serology has concentrated previously on the detection of antibodies. However, it is possible that detection of specific fungal antigens in circulation may lead to a closer understanding of clinical events such as the dermatophyte intradermal reactions as well as immune function, including cellular immunity, in infected subjects.

This work was supported by a grant from the Medical Research Council of Great Britain. We wish to thank Dr B. S. Drasar (London School of Hygiene and Tropical Medicine) for helpful discussion and Professor M. J. R. Healy (London School of Hygiene and Tropical Medicine) for helpful advice in statistical analyses. 


\section{REFERENCES}

Allen, D. E., Snyderman, R., Medows, L. \& PINNELL, S. R. (1977). Generalized Microsporum audouinii infection and depressed cellular immunity associated with a missing factor required for lymphocyte blastogenesis. American Journal of Medicine 63, 991-999.

Baldo, B. A., Fletcher, T. C. \& Pepys, J. (1977) Isolation of a peptido polysaccharide from dermatophyte Epidermophyton floccosum and a study of its reaction with human C-reactive protein and a mouse anti-phosphorylcholine myeloma serum. Immunology 32, 831-841.

BRUNDISH, D. E. \& BADDILEY, J. (1968). Pneumococcal C-substance, a ribitol teichoic acid containing choline phosphate. Biochemical Journal 110, 573582.

Calderon, R. A. \& Hay, R. J. (1984a). Cell-mediated immunity in experimental murine dermatophytosis. I. Temporal aspects of T-suppressor activity caused by Trichophyton quinckeanum. Immunology 53, 457464

Calderon, R. A. \& Hay, R. J. (1984b). Cell-mediated immunity in experimental murine dermatophytosis. II. Adoptive transfer of immunity to dermatophyte infection by lymphoid cells from donors with acute or chronic infections. Immunology 53, 465-472.

Calderon, R. A. \& Shennan, G. I. (1987). Production and immunological characterization of a monoclonal antibody to Trichophyton quinckeanum: interaction with phosphorylcholine-bearing components. Journal of General Microbiology 133, 2689-2698.

Forsyth, K. P., Spark, R., Kazura, J., Brown, G. V., Peters, P., Heywood, P., Dissanayake, S. \& Mitchell, G. F. (1985). A monoclonal antibodybased immunoradiometric assay for detection of circulating antigen in bancroftian filariasis. Journal of Immunology 134, 1172-1177.

GRAPPEL, S. F., BISHOP, C. T. \& BlanK, F. (1974). Immunology of dermatophytes and dermatophytosis. Bacteriological Reviews 38, 222-250.

Green, F. \& BALISH, E. (1979). Suppression of in vitro lymphocyte transformation during an experimental dermatophyte infection. Infection and Immunity 26, $554-562$.

Hanifin, J. M., Ray, L. F. \& Lobitz, W. C. (1974). Immunological reactivity in dermatophytosis. British Journal of Dermatology 90, 1-8.

Hay, R. J., Reid, S., Talwat, E. \& Macnamara, K. (1983). Immune response of patients with tinea imbricata. British Journal of Dermatology 108, 581 586.

Hay, R. J., Reid, S., Talwat, E. \& Macnamara, K. (1984). Endemic tinea imbricata - a study on Goodenough Island, Papua New Guinea. Transactions of the Royal Society of Tropical Medicine and Hygiene 78, 246-251.

Jones, H. E., ReinhaRdT, J. H. \& Rinaldi, M. G. (1974). Acquired immunity to dermatophytes. Archives of Dermatology 109, 840-848.

KaPlan, M. H. \& Volanakis, J. E. (1974). Interaction of $\mathrm{C}$-reactive protein complexes with the complement system. Journal of Immunology 112, 2135-2147.

LEPPER, A. W. D. (1969). Immunological aspects of dermatophytoses in animals and man. Review of Medical and Veterinary Mycology 6, 435-446.

Markwell, M. A. \& Fox, C. F. (1978). Surface specific iodination of membrane proteins of viruses and eucaryotic cells using 1,3,4,6-tetrachloro- $3 \alpha, 6 \alpha-$ diphenylglycoluril. Biochemistry 17, 4807-4817.

Pery, P., Petit, A., Poulain, J. \& Luffau, G. (1974) Phosphorylcholine bearing components in homogenates of nematodes. European Journal of Immunology 4, 637-639.

SVEJGAARD, E. (1985). Immunologic investigations of dermatophytes and dermatophytosis. Seminars in Dermatology 4, 201-221.

Walters, B. A., Chick, J. E. D. \& Halliday, W. J. (1974). Cell-mediated immunity and serum blocking factors in patients with chronic dermatophyte infections. International Archives of Allergy and Applied Immunology 46, 849-857. 